OPEN ACCESS

Edited by:

Yong Wang,

Lanzhou Institute of Chemical Physics

(CAS), China

Reviewed by:

Wei Li,

Nanjing University, China

Dongqi Wang,

University of Chinese Academy of

Sciences, China

*Correspondence:

Miquel Solà

miquel.sola@udg.edu

Specialty section:

This article was submitted to

Theoretical and Computational

Chemistry

a section of the journal

Frontiers in Chemistry

Received: 18 February 2017

Accepted: 10 March 2017

Published: 24 March 2017

Citation:

Solà M (2017) Why Aromaticity Is a

Suspicious Concept? Why?

Front. Chem. 5:22.

doi: 10.3389/fchem.2017.00022

\section{Why Aromaticity Is a Suspicious Concept? Why?}

\author{
Miquel Solà * \\ Institut de Química Computacional i Catàlisi and Departament de Química, Universitat de Girona, Girona, Spain
}

Keywords: aromaticity, conjugation, hyperconjugation, multidimensional character, indicators of aromaticity

From time to time I have the opportunity to give lectures on topics related to aromaticity. Quite often in these occasions I get comments from the audience complaining about the fact that aromaticity is not a well-defined concept. My usual answer is that the most fruitful concepts in chemistry share the same lack of strict definition (Grunenberg, 2017). In one of these occasions, the comment was formulated by someone who give a talk the day before justifying all the results he/she obtained using the concept of hyperconjugation. His/her comment was a little bit irritating to me because, in a way, he/she was saying I am a serious scientist because I am working with rigorous concepts like hyperconjugation whereas you are a kind of pseudoscientist playing with floppy concepts like aromaticity. Was he/she right? I do not think so.

Conjugation involves interactions (electron delocalization) between $\pi$-orbitals, although its definition can also be extended to p-orbitals to cover lone pair interactions with the $\pi$-system. Hyperconjugation accounts for the interaction between two orbitals with $\pi$-symmetry where one or both of them come from a saturated moiety (Mulliken, 1939; Mulliken et al., 1941). It can also be defined as the interaction between the orbitals involved in a $\sigma$-bond (usually $\mathrm{C}-\mathrm{H}$ or $\mathrm{C}-\mathrm{C}$ ) with those related with an adjacent $\pi$-bond (usually $\mathrm{C}=\mathrm{C}$ ) or another $\sigma$-bond. Aromaticity is conjugation (and in some cases hyperconjugation) that generates closed two- and threedimensional electronic circuits. Conjugation, hyperconjugation, and aromaticity lead to stabilizing interactions that influence the geometry, electron density, dissociation energies or nuclear magnetic resonance properties among many other physicochemical observables. Despite their importance and widespread use, neither hyperconjugation nor aromaticity have a strict physical definition and, therefore, these properties cannot be experimentally directly measured. These two properties share the same origin that is stabilization due to electron delocalization. Indeed, differences between these two concepts are minor as compared to similarities. Thus, the claim that one property is more rigorous than the other is totally unfounded.

The above-mentioned anecdote together with the existence of a series of papers (Balaban, 1980; Lloyd, 1996; Hoffmann, 2015) discussing the concept of aromaticity point out that aromaticity for some chemists is a controversial concept, while parent concepts like conjugation or hyperconjugation are not. Why? In the next paragraphs, I pointed out possible explanations to this fact and I propose ways of action to improve the prestige of this concept.

\section{POSSIBLE REASONS FOR THE LOW REPUTATION OF THE AROMATICITY CONCEPT}

The reasons for aromaticity being perceived by some members of the chemical community as questionable are:

Article Title Justification: On 27th April 2011, after Real Madrid vs Barcelona (0-2) match in Champions League, the trainer of the Real Madrid, José Mourinho, complained about UEFA referees saying: "Why? Why? Why Ovrebo? Why Busacca? Why De Bleeckere? Why Stark? Why?" The title is inspired in his speech and it is a homage to the unforgettable Barcelona 2010-11 team. 


\section{Too Many Aromaticity Descriptors}

Probably, the problem with aromaticity is not the concept itself, but the way aromaticity is characterized. No single property exists that could be taken as a direct measure of aromaticity. The evaluation of global or local aromaticity of a molecule is usually done indirectly by measuring some physicochemical property that reflects a manifestation of its aromatic character. This leads to a large number of classical structural (Krygowski and Cyrański, 2001; Krygowski et al., 2014), magnetic (Mitchell, 2001; Chen et al., 2005; Gershoni-Poranne and Stanger, 2015), energetic (Cyrański, 2005), electronic (Poater et al., 2005; Feixas et al., 2015), and reactivity-based (Mucsi et al., 2007) measures of aromaticity. In my opinion, there are too many indicators of aromaticity. An extensive but not exhaustive list (Solà, 2017) of acronyms includes ASE, RE, ISE, AI, HOMA, Julg index, Jug index, Bird index, PDI, FLU, FLU ${ }_{\pi}, \mathrm{MCI}, \mathrm{I}_{\text {ring }}, \mathrm{I}_{\mathrm{NG}}, \mathrm{I}_{\mathrm{NB}}, \mathrm{EDDB}$, AV1245, ELF $\pi$, ATI, $\theta$, PLR, $\eta, \rho_{\mathrm{RCP}}, \wedge$, ACID, ARCS, NICS, $\mathrm{NICS}_{z Z}, \mathrm{NICS}_{\pi}, \mathrm{NICS}-\mathrm{XY}$-scan... The problem is that not all of them give the same ordering by aromaticity of a series of rings or molecules adding confusion to the field (Balaban, 1980; Lloyd, 1996; Poater et al., 2004). And the reason is that all indices are just approximations to the problem of measuring aromaticity and some of them are not useful for certain situations (for instance, to detect the aromaticity of transition states in cycloaddition reactions). Other indices are simply not good enough to provide reliable results. This is particularly the case if we want to quantify the aromaticity of metalloaromatic compounds (Feixas et al., 2013) because most of the methods to measure aromaticity were developed for the classical aromatic organic molecules and they cannot be directly applied to metallic clusters. For these species, the electronic indices and magnetic measures are likely the best choices (Feixas et al., 2010).

\section{The Multidimensional Character of Aromaticity}

In relation with the previous point, many times the apparent contradictions found among differently based indices are overcome by addressing to the so-called multidimensional character of aromaticity (Katritzky et al., 1989, 1998, 2001; Jug and Köster, 1991; Krygowski and Cyrański, 2001; Cyrański et al., 2002). According to this view, different indices afford divergent orderings since one compound may be more aromatic than other in one dimension and less aromatic in another (Krygowski et al., 2000). The problem with this view is that, in principle, one could get any ordering of aromaticity provided one looks at the correct direction in the multidimensional space. If we accept the multidimensional character of aromaticity, then this concept becomes quite useless because one can justify almost any result. Some years ago, Bultinck et al. (Bultinck et al., 2006; Bultinck, 2007) already warned about the use of the multidimensional character of aromaticity as a generic excuse to consider any aromaticity index a good descriptor of aromaticity irrespective of the results obtained.

\section{Too Many Types of Aromaticity}

The list of different types of aromaticity is also very broad (Solà, 2017). Among them we can cite Hückel aromaticity,
Möbius aromaticity, excited state aromaticity, Hückel-Baird hybrid aromaticity, homoaromaticity, heteroaromaticity, claromaticity, three-dimensional aromaticity, spherical aromaticity, cubic aromaticity, octahedral aromaticity, $\sigma$ aromaticity, $\delta$-aromaticity, multiple aromaticity, conflicting aromaticity, metalloaromaticity, chelatoaromaticity, quasiaromaticity, transition state aromaticity, hyperaromaticity... The adjective added to aromaticity in each case helps to describe a particular situation. In a sense, they are totally justified, however, the existence of so many types of aromaticity can be perceived as hectic.

\section{The Unwarranted Use of Aromaticity}

The link between aromaticity and stability is well-established. However, among a series of isomers or different electronic states, not always the most stable is the most aromatic. Aromaticity is just one more of the many factors that affect the relative energies of isomers. Other aspects, such as strain energy, hyperconjugation, the presence of hydrogen bonds, long-range interactions, and so forth, may have, in many cases, a greater influence. Aromaticity cannot explain all observed differences. It should not come as a surprise to find isomerization energies that cannot be justified from the different aromatic character of the isomers. For instance, N-substituted imidazoles are more stable than the corresponding pyrazoles although the higher stability of imidazoles is not due to the higher aromaticity of imidazole rings but a weaker $\mathrm{N}-\mathrm{N}$ bond found in the pyrazole rings (Curutchet et al., 2011).

\section{POSSIBLE SOLUTIONS AND RECOMMENDATIONS}

Possible recommendations that may help to improve the prestige of aromaticity are:

\section{Propose New Descriptors of Aromaticity Only When Justified}

As said before, there are too many indicators of aromaticity. New indicators are welcome but only when they improve the currently existing ones because they are cheaper to compute and have a similar quality to those previously defined or they have a better performance. To assess the quality of the descriptors, the best option is to employ a set of aromaticity tests (Feixas et al., 2008; Solà et al., 2010) that are designed based on the accumulated chemical experience about the expected aromaticity trends in a given series of compounds. The larger the number of tests passed, the better the indicator (Feixas et al., 2008, 2010; Solà et al., 2010).

\section{Avoid Using the Excuse of the Multidimensional Character of Aromaticity}

Available indices of aromaticity do not always give consistent results among themselves (Balaban, 1980; Lloyd, 1996; Poater et al., 2004; Zhao et al., 2017). Thus, for instance, predictions based on magnetic criteria of aromaticity often deviates from those based on energetic grounds (Aihara, 2006). In some cases, contradictions found among indices are justified by 
addressing to the so-called multidimensional character of aromaticity (Katritzky et al., 1989, 1998, 2001; Jug and Köster, 1991; Krygowski and Cyrański, 2001; Cyrański et al., 2002). Recent works, however, have proved that, in many cases, the contradictions between indices are due to failures of some indicators to correctly measure aromaticity and that the multidimensional character of aromaticity is not fully founded (Bultinck et al., 2006; Bultinck, 2007; Badri and Foroutan-Nejad, 2016).

\section{Using a Set of Aromaticity Indicators}

In general, it is advisable to use a set of indices based on different physicochemical properties to characterize aromatic compounds (Hoffmann et al., 1997; Poater et al., 2004; Chen et al., 2005; Tsipis, 2005; Van Droogenbroek et al., 2005; Feixas et al., 2007). When using a large set of aromaticity indicators, conclusions reached are much more reliable. In particular, one can feel especially safe about the derived conclusions when all criteria provide the same results for the set of compounds analyzed. If different criteria produce contradictory results, the conclusions, if any, are necessarily weaker.

\section{Avoid Defining New Types of Aromaticity}

As said before, the number of different types of aromaticity is probably too large. In some cases, the use of adjectives in front of the word aromaticity can be helpful. In other occasions, it is unnecessary. For instance, when we write that pyridine is a heteroaromatic molecule or when we classify metallabenzenes as metalloaromatic, we are not giving any extra information. By just calling them aromatic, it would be enough. In fact,

\section{REFERENCES}

Aihara, J.-I. (2006). Circuit resonance energy: a key quantity that links energetic and magnetic criteria of aromaticity. J. Am. Chem. Soc. 128, 2873-2879. doi: $10.1021 /$ ja056430c

Badri, Z., and Foroutan-Nejad, C. (2016). Unification of ground-state aromaticity criteria - structure, electron delocalization, and energy - in light of the quantum chemical topology. Phys. Chem. Chem. Phys. 18, 11693-11699. doi: 10.1039/C5CP05222J

Balaban, A. T. (1980). Is aromaticity outmoded? Pure Appl. Chem. 52, 1409-1429. doi: 10.1351/pac198052061409

Bultinck, P. (2007). Critical analysis of the local aromaticity concept in polyaromatic hydrocarbons. Faraday Discuss. 135, 347-365. doi: 10.1039/B609640A

Bultinck, P., Fias, S., and Ponec, R. (2006). Local aromaticity in polycyclic aromatic hydrocarbons: electron delocalization versus magnetic indices. Chem. Eur. J. 12, 8813-8818. doi: 10.1002/chem.200600541

Chen, Z., Wannere, C. S., Corminboeuf, C., Puchta, R., and Schleyer, P. v. R. (2005). Nucleus-Independent Chemical Shifts (NICS) as an aromaticity criterion. Chem. Rev. 105, 3842-3888. doi: 10.1021/cr030088

Curutchet, C., Poater, J., Solà, M., and Elguero, J. (2011). Analysis of the effects of $\mathrm{N}$-Substituents on some aspects of the aromaticity of imidazoles and pyrazoles. J. Phys. Chem. A 115, 8571-8577. doi: 10.1021/jp204263p

Cyrański, M. K. (2005). Energetic aspects of cyclic Pi-electron delocalization: evaluation of the methods of estimating aromatic stabilization energies. Chem. Rev. 105, 3773-3811. doi: 10.1021/cr0300845

Cyrański, M. K., Krygowski, T. M., Katritzky, A. R., and Schleyer, P. v. R. (2002). To what extent can aromaticity be defined uniquely? J. Org. Chem. 67, 1333-1338. doi: $10.1021 /$ jo016255s no one considers that the $\mathrm{Zn}-\mathrm{Zn}$ bond ( $\mathrm{Zhu}$ et al., 2006) is a metallocovalent bond. We simply say that it is a covalent bond. When naming aromatic compounds, one should keep nomenclature as simple as possible.

In summary, since the discovery of benzene in 1825 , aromaticity has been one of the most vexing yet fascinating concepts in chemistry. It is useful to understand the structure, stability, spectroscopy, magnetic properties, and chemical reactivity of many compounds. Like many fruitful concepts in chemistry, aromaticity is vaguely defined. However, this lack of a strict definition is not a reason strong enough to question the concept. In this article, we have listed a series of good practices that may improve the perception of this concept.

\section{AUTHOR CONTRIBUTIONS}

The author confirms being the sole contributor of this work and approved it for publication.

\section{ACKNOWLEDGMENTS}

The following organizations are thanked for financial support: The Ministerio de Economía y Competitividad (MINECO, project number CTQ2014-54306-P), the Generalitat de Catalunya (project number 2014SGR931, Xarxa de Referència en Química Teòrica i Computacional, and ICREA Academia 2014 prize), and the FEDER fund (European Fund for Regional Development) for the grant UNGI10-4E-801.

Feixas, F., Jiménez-Halla, J. O. C., Matito, E., Poater, J., and Solà, M. (2010). A test to evaluate the performance of aromaticity descriptors in all-metal and semimetal clusters. An appraisal of electronic and magnetic indicators of aromaticity. J. Chem. Theory Comput. 6, 1118-1130. doi: 10.1021/ct100034p

Feixas, F., Matito, E., Poater, J., and Solà, M. (2007). Aromaticity of distorted benzene rings. Exploring the validity of different indicators of aromaticity. J. Phys. Chem. A 111, 4513-4521. doi: 10.1021/jp0703206

Feixas, F., Matito, E., Poater, J., and Solà, M. (2008). On the performance of some aromaticity indices: a critical assessment using a test set. J. Comput. Chem. 29, 1543-1554. doi: 10.1002/jcc.20914

Feixas, F., Matito, E., Poater, J., and Solà, M. (2013). Metalloaromaticity. WIREs Comput. Mol. Sci. 3, 105-122. doi: 10.1002/wcms.1115

Feixas, F., Matito, E., Poater, J., and Solà, M. (2015). Quantifying aromaticity with electron delocalisation measures. Chem. Soc. Rev. 44, 6434-6451. doi: 10.1039/C5CS00066A

Gershoni-Poranne, R., and Stanger, A. (2015). Magnetic criteria of aromaticity. Chem. Soc. Rev. 44, 6597-6615. doi: 10.1039/C5CS00114E

Grunenberg, J. (2017). Ill-defined chemical concepts: the problem of quantification. Int. J. Quantum. Chem. 117. doi: 10.1002/qua.25359

Hoffmann, R. (2015). The many guises of aromaticity. Am. Sci. 103, 18-22. doi: $10.1511 / 2015.112 .18$

Hoffmann, R., Minkin, V. I., and Carpenter, B. K. (1997). Ockham's Razor and Chemistry. HYLE Int. J. Philos. Chem. 3, 3-28.

Jug, K., and Köster, A. M. (1991). Aromaticity as a multi-dimensional phenomenon. J. Phys. Org. Chem. 4, 163-169. doi: 10.1002/poc.610040307

Katritzky, A. R., Barczynski, P., Musumarra, G., Pisano, D., and Szafran, M. (1989). Aromaticity as a quantitative concept. 1. A statistical demostration of the orthogonality of "classical" and "magnetic" aromaticity in five- and sixmembered heterocycles. J. Am. Chem. Soc. 111, 7-15. doi: 10.1021/ja00183a002 
Katritzky, A. R., Jug, K., and Oniciu, D. C. (2001). Quantitative measures of aromaticity for mono-. bi-, and tricyclic penta- and hexaatomic heteroaromatics ring systems and their interrelationships. Chem. Rev. 101, 1421-1449. doi: $10.1021 / \mathrm{cr} 990327 \mathrm{~m}$

Katritzky, A. R., Karelson, M., Sild, S., Krygowski, T. M., and Jug, K. (1998). Aromaticity as a quantitative concept. 7. Aromaticity reaffirmed as a multidimensional characteristic. J. Org. Chem. 63, 5228-5231. doi: $10.1021 /$ jo $970939 \mathrm{~b}$

Krygowski, T. M., and Cyrański, M. K. (2001). Structural aspects of aromaticity. Chem. Rev. 101, 1385-1419. doi: 10.1021/cr990326u

Krygowski, T. M., Cyrański, M. K., Czarnocki, Z., Häfelinger, G., and Katritzky, A. R. (2000). Aromaticity: a theoretical concept of immense practical importance. Tetrahedron 56, 1783-1796. doi: 10.1016/S0040-4020(99)00979-5

Krygowski, T. M., Szatylowicz, H., Stasyuk, O. A., Dominikowska, J., and Palusiak, M. (2014). Aromaticity from the viewpoint of molecular geometry: application to planar systems. Chem. Rev. 114, 6383-6422. doi: 10.1021/cr400252h

Lloyd, D. (1996). What is aromaticity? J. Chem. Inf. Comp. Sci. 36, 442-447. doi: $10.1021 / \mathrm{ci} 950158 \mathrm{~g}$

Mitchell, R. H. (2001). Measuring aromaticity by NMR. Chem. Rev. 101, 1301-1315. doi: $10.1021 / \mathrm{cr} 990359$

Mucsi, Z., Viskolcz, B., and Csizmadia, I. G. (2007). A Quantitative scale for the degree of aromaticity and antiaromaticity: a comparison of theoretical and experimental enthalpies of hydrogenation. J. Phys. Chem. A 111, 1123-1132. doi: $10.1021 /$ jp0657686

Mulliken, R. S. (1939). Intensities of electronic transitions in molecular spectra IV. Cyclic dienes and hyperconjugation. J. Chem. Phys. 7, 339-352. doi: $10.1063 / 1.1750446$

Mulliken, R. S., Rieke, C. A., and Brown, W. G. (1941). Hyperconjugation. J. Am. Chem. Soc. 63, 41-56. doi: 10.1021/ja01846a008

Poater, J., Duran, M., Solà, M., and Silvi, B. (2005). Theoretical evaluation of electron delocalization in aromatic Molecules by Means of Atoms in Molecules (AIM) and Electron Localization Function (ELF) topological approaches. Chem. Rev. 105, 3911-3947. doi: 10.1021/cr030085x
Poater, J., García-Cruz, I., Illas, F., and Solà, M. (2004). Discrepancy between common local aromaticity measures in a series of carbazole derivatives. Phys. Chem. Chem. Phys. 6, 314-318. doi: 10.1039/B309965B

Solà, M. (2017). "Aromaticity," in Encyclopedia of Physical Organic Chemistry, Vol. 1, ed Z. Wang (Weinheim: John Wiley and Sons), 511-542.

Solà, M., Feixas, F., Jiménez-Halla, J. O. C., Matito, E., and Poater, J. (2010). A critical assessment of the performance of magnetic and electronic indices of aromaticity. Symmetry 2, 1156-1179. doi: 10.3390/sym2021156

Tsipis, C. A. (2005). DFT Study of "all-metal" aromatic compounds. Coord. Chem. Rev. 249, 2740-2762. doi: 10.1016/j.ccr.2005.01.031

Van Droogenbroek, J., Van Alsenoy, C., and Blockhuys, F. (2005). Multidimensional description of the aromaticity in planar five-membered NSNS ring systems. J. Phys. Chem. A 209, 4847-4851. doi: 10.1021/jp04 43714

Zhao, L., Grande-Aztatzi, R., Foroutan-Nejad, C., Ugalde, J. M., and Frenking, G. (2017). Aromaticity, the Hückel $4 \mathrm{n}+2$ rule and magnetic current. Chem. Select 2, 863-870. doi: $10.1002 /$ slct. 201602080

Zhu, Z., Wright, R. J., Olmstead, M. M., Rivard, E., Brynda, M., and Power, P. P. (2006). A zinc-zinc-bonded compound and its derivatives bridged by one or two hydrogen atoms: a new type of $\mathrm{Zn}-\mathrm{Zn}$ Bonding. Angew. Chem. Int. Ed. 45, 5807-5810. doi: 10.1002/anie.200601926

Conflict of Interest Statement: The author declares that the research was conducted in the absence of any commercial or financial relationships that could be construed as a potential conflict of interest.

Copyright $\odot 2017$ Solà. This is an open-access article distributed under the terms of the Creative Commons Attribution License (CC BY). The use, distribution or reproduction in other forums is permitted, provided the original author(s) or licensor are credited and that the original publication in this journal is cited, in accordance with accepted academic practice. No use, distribution or reproduction is permitted which does not comply with these terms. 